\title{
Infusion or Flow Problem
}

National Cancer Institute

\section{Source}

National Cancer Institute. Infusion or Flow Problem. NCI Thesaurus. Code C63075.

Problem associated with the device failing to deliver liquids or gases as intended (e.g. delivering drugs at incorrect rate, problems with drawing fluid from a system.) 